\title{
Induction of Immunogenic Cell Death of Esophageal Squamous Cell Carcinoma by 5-Fluorouracil and Cisplatin
}

\author{
JUNYA NISHIMURA*, SOTA DEGUCHI*, HIROAKI TANAKA, YOSHIHITO YAMAKOSHI, MAMI YOSHII, \\ TATSURO TAMURA, TAKAHIRO TOYOKAWA, SHIGERU LEE, KAZUYA MUGURUMA and MASAICHI OHIRA \\ Department of Gastroenterological Surgery, Osaka City University Graduate School of Medicine, Osaka, Japan
}

\begin{abstract}
Background/Aim: Neoadjuvant chemotherapy (NAC) using 5-FU (5-fluorouracil)/CDDP (cisplatin) is a standard therapy for stage II/III thoracic esophageal squamous cell carcinoma (ESCC) in Japan. The aim of this study was to investigate whether 5-FU/CDDP could induce immunogenic cell death in ESCC cell lines. Materials and Methods: Tumor samples for immunohistochemistry were obtained from 50 patients (mean age=63.1 years) with pathological stage O-IVa ESCC who underwent NAC followed by surgery. Cell lines T.T and KYSE30 were used for the in vitro experiments. Results: The concentrations of $H M G B 1$ were elevated in the cell line supernatants treated with 5-FU/CDDP. 5-FU/CDDP treated dendritic cells (DCs) showed a mature phenotype, and enhanced $T$ cell proliferation capacity. In addition, mature DCs were observed in surgical specimens with a histological response after treatment with 5-FU/CDDP chemotherapy. Conclusion: 5-FU/CDDP could induce immunogenic cell death in the tumor microenvironment of ESCC.
\end{abstract}

5-FU (5-fluorouracil)/CDDP (cisplatin) has been used as neoadjuvant chemotherapy (NAC) for the treatment of stage II/III thoracic esophageal squamous cell carcinoma (ESCC) in Japan (1). NAC for esophageal cancer has the advantage of suppressing micrometastasis due to the achievement of tumor downstaging before surgery (2).

This article is freely accessible online.

*These Authors contributed equally to this work.

Correspondence to: Hiroaki Tanaka, Department of Gastroenterological Surgery, Osaka City University Graduate School of Medicine, Asahimachi 1-4-3, Abeno-ku, Osaka 545-8585, Japan. Tel: +81 666453838, Fax: +81 666466450, e-mail: hiroakitan@med.osaka-cu.ac.jp

Key Words: Immunogenic cell death, dendritic cell, LAMP-3, HMGB1, neoadjuvant chemotherapy.
Immunotherapy is expected to be one of the most important treatments for ESCC; however, the interaction between immunotherapy and chemotherapy is still unknown. In general, because cytotoxic anticancer drugs damage normal bone marrow cells as well as cancer cells, they have been thought to induce immunosuppression due to lymphopenia. On the other hand, it is considered that chemotherapy can induce immunogenic cell death (ICD) of tumor cells, which triggers the $\mathrm{T}$ cell immunity mediated by danger-associated molecular patterns (DAMPs), which can activate immune cells, including dendritic cells (DCs) (3). One of the DAMPs is high-mobility group box 1 protein (HMGB1). Extracellular HMGB1 enhances dendritic cell antigen presentation and promotes the so-called maturation of DCs (4).

DC maturation includes the enhanced expression of MHCs, costimulatory molecules such as CD80, CD86 and lysosome-associated membrane glycoprotein 3 (LAMP-3) (5). LAMP-3, which is normally scattered within lysosomes on the surface of dendritic cells, is known to appear as a component of the MHC-II molecule during antigen phagocytosis and maturation of dendritic cells $(6,7)$. Thus, LAMP-3 has been considered as a marker of DC maturation.

The local immune status is an important prognostic factor for various types of tumor, including ESCC (8). We expect that in addition to their antitumor cytotoxicity effect, chemical drugs may induce ICD in ESCC. However, little information is available regarding ICD in ESCC. The aim of this study was to explore the influence of chemotherapy on local infiltrating immune cells in ESCC.

\section{Materials and Methods}

Clinical samples for immunohistochemistry. Tumor samples for immunohistochemistry were obtained from 50 patients (mean age $=63.1$ years) with pathological stage 0-IVa ESCC who underwent NAC (5-FU+CDDP or 5-FU+nedaplatin) followed by surgical treatment at the Department of Surgical Oncology, Osaka City University Hospital, between 2000 and 2015. The median follow-up time was 25 months. 
Cell line. The "T.T" and KYSE 30 ESCC cell lines were used in this study. T.T human esophageal squamous cell carcinoma cells were obtained from the Health Science Research Resources Bank (Osaka, Japan). KYSE30 cells were obtained from JCRB Cell bank (Japan) (9). Cells were cultured at $37^{\circ} \mathrm{C}$ and in $5 \% \mathrm{CO}_{2}$. The medium used was Dulbecco's modified Eagle's medium (DMEM; Bioproducts, Walkersville, MD, USA) supplemented with $10 \%$ fetal bovine serum (FBS; Gibco, Grand Island, NY, USA), $100 \mathrm{IU} / \mathrm{ml}$ of penicillin (ICN Biomedicals, Costa Mesa, CA, USA), $100 \mathrm{mg} / \mathrm{ml}$ of streptomycin (ICN Biomedicals, Aurora, OH, USA) and $0.5 \mathrm{mM}$ sodium pyruvate (Bioproducts).

The concentrations of 5-FU and cisplatin used in the in vitro experiments were evaluated for apoptosis by using Annexin V/7AAD staining and $30 \mu \mathrm{mol} / \mathrm{l}$ for $48 \mathrm{~h}$ was determined to be optimal for both drugs.

Isolation of DCs from surgical specimens. Surgical specimens of nine patients with histologically diagnosed primary ESCC were subjected to flow cytometry. The patients who received neoadjuvant chemotherapy (5-FU/CDDP-based chemotherapy) included 4 patients with stage II disease and 2 patients with stage III disease. None of the patients had received any treatment before this study. Tumors were diagnosed histologically based on the 11th Edition of the Japanese Classification of Esophageal Cancer. Primary ESCC cells were obtained from ESCC patients undergoing surgery. The resected tumors were weighed, minced into small pieces $(1-3 \mathrm{~mm})$, and then mechanically minced into smaller pieces in PBS $+2 \mathrm{nmol} / 1$ EDTA. The tumor portions were then placed in an enzyme solution (Collagenase D), incubated $\left(37^{\circ} \mathrm{C}\right)$ for $30 \mathrm{~min}$ and then, mixed again twice. HLA-DR+ cells were enriched by positive magnetic bead selection (MACS; Miltenyi-Biotec, San Diego, CA, USA) using PElabeled primary monoclonal antibodies and anti-PE microbeads together with LS separation columns and a Vario MACS ${ }^{\circledR}$ magnet.

Immunohistochemistry. Tumor specimens in paraffin-embedded blocks were cut into $4-\mu \mathrm{m}$-thick sections. Nonspecific binding was blocked using nonspecific staining blocking reagent (DAKO, Kyoto, Japan). The sections were then reacted with mouse monoclonal antiLAMP-3 antibody (clone: 16H11.2; Merck, Darmstadt, Germany) and rabbit monoclonal anti-CD8 antibody (clone: EP1150Y; Abcam, Cambridge, UK) at $4^{\circ} \mathrm{C}$ overnight. Sections were incubated with secondary antibodies for $10 \mathrm{~min}$ at room temperature. After washing in phosphate-buffered saline (PBS), the sections were visualized using 3-3'-diamino-benzidine (DAB) for $5 \mathrm{~min}$ and counterstained with hematoxylin. We counted the average number of LAMP-3positive and CD8-positive cells in 5 randomly selected fields under a light microscope at $\times 400$ magnification.

Treatment with cancer cells. T.T cells $\left(5 \times 10^{5}\right)$ were plated in $1 \mathrm{ml}$ of full medium treated with 5-FU and/or CDDP $(30 \mu \mathrm{M})$. Supernatants were collected after $48 \mathrm{~h}$, dying tumor cells were removed by centrifugation, and the supernatants were isolated and immediately frozen. The quantification of HMGB1 in the supernatants was assessed by ELISA, which was performed according to the manufacturer's instructions (R\&D systems, Minneapolis, MN, USA). DCs were generated by culturing purified CD14+ cells isolated from buffy coats in the presence of granulocyte-macrophage colony-stimulating factor (GM-CSF: Miltenyi- Biotec, San Diego, CA, USA) and interleukin-4 (IL-4: Miltenyi- Biotec). The phenotypical assessment of DC maturation after $24 \mathrm{~h}$ of co-culture with supernatants of chemical-treated T.T cells was performed by using flow cytometry. Briefly, cells were washed in PBA, incubated with Fc-receptor blocking buffer (2\% HS in PBS) for $15 \mathrm{~min}$ at $4^{\circ} \mathrm{C}$ and subsequently stained with primary antibodies in PBA for $30 \mathrm{~min}$ at $4^{\circ} \mathrm{C}$. The following monoclonal directly labeled anti-human antibodies were used: anti-CD11c-APC (clone: B-ly-6; BD Pharmingen, Franklin Lakes, NJ, USA), antiCD208-PE (clone: I10-1112; BD Pharmingen), anti-CD274-APC (clone: MI-H1; BD Pharmingen), anti-CD80-BB515 (clone: L307.4; BD Pharmingen), anti-CD86-BV421 (clone: 2331 (FUN-1); BD Pharmingen), and anti-HLA-DR-FITC (clone: G46-6; BD Pharmingen). The geometric mean fluorescence intensity (Geo MFI) of maturation markers was assessed in $\mathrm{CD} 11 \mathrm{c}+$ populations. As a positive control, DCs were stimulated with $10 \mu \mathrm{g} / \mathrm{ml}$ lipopolysaccharide (LPS: Sigma-Aldrich, St. Louis, MO, USA).

Assays of cytokine production. Monocyte-derived DCs were cultured for 5 days and adjusted to a final concentration of $1 \times 10^{6}$ cells $/ \mathrm{ml}$ in 24-well plates. Next, an equivalent amount of untreated control, 5-FU and/or CDDP supernatant and $10 \mu \mathrm{g} / \mathrm{ml}$ LPS was added to separate wells of the 24-well plates. Supernatants from the designated wells were harvested after $24 \mathrm{~h}$ for the quantification of cytokines (e.g., IL-1 $\beta$, IL-6, IL-10) using an ELISA kit (R\&D Systems, Minneapolis, MN, USA).

Mixed lymphocyte reaction (MLR). Allogenic PBLs were stained with $5 \mu \mathrm{M}$ CFSE (Invitrogen, Carlsbad, CA, USA), according to the manufacturer's instructions and added to the DCs at a ratio of 10:1 (Lymphocytes: DCs), for an additional 5-day period. After 5 days, co-cultures were stained with a primary anti-CD3-APC antibody (clone: G155-178; BD Pharmingen, Franklin Lakes, NJ, USA) and analyzed by flow cytometry. The percentage of proliferating $\mathrm{T}$ cells $\left(\mathrm{CD}^{+}\right)$was determined by assessing the CFSE dilution in the fraction of $\mathrm{CD}^{+}$cells.

FITC dextran. After $24 \mathrm{~h}$ of incubation with supernatants, monocytederived DCs were incubated for $1 \mathrm{~h}$ with $1 \mathrm{mg} / \mathrm{ml}$ of fluorescein isothiocyanate (FITC)-conjugated dextran (DX) (70,000 Dalton molecular weight, Sigma-Aldrich) at $37^{\circ} \mathrm{C}$, washed extensively, and then examined to detect FITC signaling by $\mathrm{CD} 11 \mathrm{c}^{+}$cells.

Ethical approval and informed consent. This study's retrospective protocol was approved by the Osaka City University Ethics Committee (Osaka, Japan), and a written informed consent was obtained from all patients. All volunteers provided oral and written informed consent and agreed to the use of their samples for scientific research.

Statistical analysis. The Mann-Whitney test was used to assess the associations between the expression of LAMP-3 and the clinicopathological features. The Kaplan-Meier method was used to produce overall survival (OS) curves, and a log-lank test was used to assess the significance of differences in survival. The day of surgery was used as the starting point for measuring OS. A Cox proportional regression model was used for the univariate and multivariate analyses of prognostic factors. $p$-Values of $<0.05$ were considered to indicate statistical significance. The degree of infiltration between the number of LAMP-3 DCs and CD8 T cells was compared by Spearman's correlation coefficient. All statistical analyses were performed using the JMP software program (SAS Institute, Cary, NC, USA). 

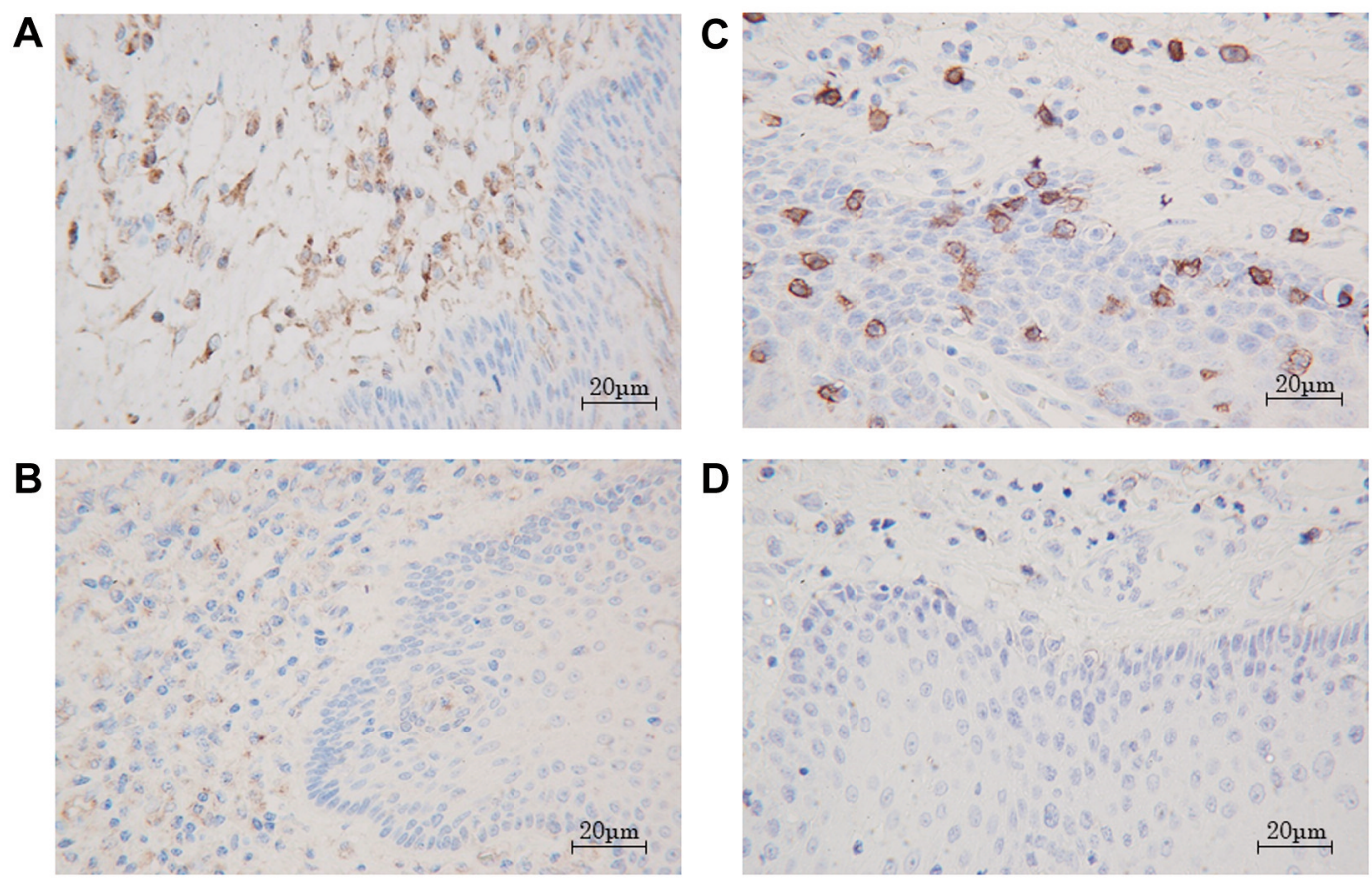

Figure 1. Immunohistochemical staining of LAMP-3 and CD8 T cell in esophagus squamous cell carcinoma. LAMP-3 dendritic cells were mainly distributed in the peritumoral area, but were sparsely present in the intratumoral area (A: high infiltration, B: low infiltration $\times 200)$. CD8 T cells were found in both the peritumoral and intratumoral areas (C: high infiltration, D: low infiltration $\times 200$ ).

\section{Results}

Correlation of LAMP-3 expression with prognosis. In the immunohistochemical analysis, LAMP-3-positive cells were predominantly observed in the peritumoral area and CD8-T cells were in the intratumoral area. These cells appear morphologically as dendritic cells because of their dendrites (Figure 1A, B). We divided the entire cohort into two groups according to the median number of tumor-infiltrating LAMP3 DCs and CD8-T cells. The correlation between the number of tumor-infiltrating LAMP-3 DCs/CD8-T cells and the clinicopathological features is shown in Table I. The tumor infiltration by LAMP-3 DCs in patients with $\mathrm{pN} 3$ and advanced stage was significantly decreased in comparison to those with pN0 and early stage. We found that infiltration of LAMP-3 DCs was increased in 32 cases with any histological changes.

Patients with high infiltration of peritumoral-LAMP-3 DCs had a significantly better prognosis in comparison to those with low infiltration (Figure 2). The 5-year survival rates in patients with high and low LAMP-3 DC infiltration were $71 \%$ and $38 \%$, respectively. We observed that the number of infiltrating LAMP-3 DCs and CD8-T cells had a weak positive correlation $(\mathrm{r}=0.20, p=0.038)$. Eighteen of the 25 patients with high DC infiltration belonged to the CD8high infiltration group.

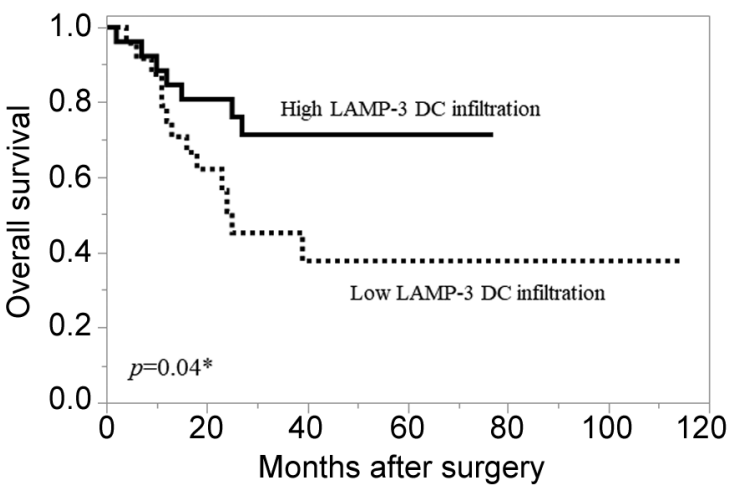

At risk $(n)$

$\begin{array}{llllllll}\text { High } & 26 & 19 & 11 & 5 & 1 & 1 & 1 \\ \text { Low } & 24 & 12 & 5 & 3 & 1 & 1 & 1\end{array}$

Figure 2. Kaplan-Meier curves of overall survival in patients with ESCC. The survival rate of patients in the high peritumoral-DC group was significantly higher than that of patients in the low peritumoralLAMP-3 DC group ( $p=0.04$, log-rank test).

With regard to the pathological response to NAC, thirteen patients showed downstaging. There was no correlation between downstaging by NAC and the degree of infiltration of LAMP-3 DCs. 
Table I. Correlations between clinicopathological factors and $D C S / C D 8^{+} T$ cells infiltration.

\begin{tabular}{|c|c|c|c|c|c|c|c|c|}
\hline & & \multirow[t]{2}{*}{$\mathrm{N}$} & \multicolumn{3}{|c|}{ LAMP-3 DCs } & \multicolumn{3}{|c|}{$\mathrm{CD} 8+\mathrm{T}$ cells } \\
\hline & & & Low & High & $p$-Value & Low & High & $p$-Value \\
\hline \multirow[t]{2}{*}{ Age } & $<70$ & 37 & 18 & 19 & & 17 & 20 & \\
\hline & $\geq 70$ & 13 & 6 & 7 & 0.88 & 8 & 5 & 0.33 \\
\hline \multirow[t]{2}{*}{ Gender } & Male & 45 & 21 & 24 & & 25 & 20 & \\
\hline & Female & 5 & 3 & 2 & 0.57 & 0 & 5 & $0.02 *$ \\
\hline \multirow[t]{3}{*}{ Location } & $\mathrm{Ut}$ & 4 & 2 & 2 & & 2 & 2 & \\
\hline & Mt & 26 & 15 & 11 & & 14 & 12 & \\
\hline & $\mathrm{Lt} / \mathrm{Ae}$ & 18 & 7 & 11 & 0.47 & 8 & 10 & 0.83 \\
\hline \multirow[t]{2}{*}{ Length } & $<5 \mathrm{~cm}$ & 20 & 8 & 12 & & 6 & 14 & \\
\hline & $\geq 5 \mathrm{~cm}$ & 20 & 12 & 8 & 0.21 & 12 & 18 & 0.06 \\
\hline \multirow[t]{2}{*}{ pT category } & $\mathrm{T} 1-2$ & 21 & 8 & 13 & & 7 & 14 & \\
\hline & T3-4 & 29 & 16 & 13 & 0.23 & 18 & 11 & $0.04 *$ \\
\hline \multirow[t]{3}{*}{ pN category } & N 0 & 12 & 5 & 7 & & 5 & 5 & \\
\hline & N 1-2 & 27 & 13 & 14 & & 12 & 14 & \\
\hline & N3-4 & 10 & 9 & 1 & $0.04 *$ & 8 & 6 & 0.8 \\
\hline \multirow[t]{5}{*}{ p Stage } & Stage 0 & 2 & 0 & 2 & & 1 & 1 & \\
\hline & Stage I & 3 & 2 & 1 & & 1 & 2 & \\
\hline & Stage II & 14 & 3 & 11 & & 7 & 7 & \\
\hline & Stage III & 19 & 12 & 7 & & 12 & 7 & \\
\hline & Stage IV & 12 & 11 & 1 & $<0.01 *$ & 8 & 4 & 0.78 \\
\hline \multirow[t]{2}{*}{ Lymphatic invasion } & - & 15 & 6 & 9 & & 4 & 10 & \\
\hline & + & 35 & 18 & 17 & 0.54 & 20 & 15 & 0.12 \\
\hline \multirow[t]{2}{*}{ Venous invasion } & - & 40 & 19 & 21 & & 18 & 21 & \\
\hline & + & 10 & 5 & 5 & 0.62 & 6 & 4 & 0.44 \\
\hline \multirow[t]{2}{*}{ Histology } & Differentiated & 27 & 12 & 15 & & 16 & 12 & \\
\hline & Undifferentiated & 21 & 11 & 10 & 0.51 & 9 & 12 & 0.37 \\
\hline \multirow[t]{2}{*}{ Histological grade } & 0 & 16 & 11 & 5 & & 8 & 8 & \\
\hline & $1 a-3$ & 32 & 12 & 20 & $0.04 *$ & 17 & 15 & 0.84 \\
\hline
\end{tabular}

*Statistically significant.

Induction of immunogenic cell death of cancer cells by 5 FU/CDDP treatment. We used two esophageal squamous cell carcinoma cell lines, T.T and KYSE 30, to investigate the effect of 5-FU/CDDP chemotherapy on cancer cells. In both TT and KYSE 30, HMBG1 production was increased by chemotherapy treatment. The combination of 5-FU and CDDP was more effective than either alone (Figure 3 ). In both T.T and KYSE 30, IL-6 was increased by the chemotherapy treatment (Figure 3). For IL-1B and IL-10, there were statistically significant increases in KYSE $(p<0.05)$, and no significant differences were observed in T.T. Despite these differences in cell lines, it was suggested that 5-FU/CDDP treatment affected the production of inflammatory cytokines.

We found that the release of HMGB1 into the cell supernatants of T.T and KYSE at $48 \mathrm{~h}$ after treatment with 5FU and/or CDDP was significantly increased in comparison to the release in the untreated control group $(p<0.05)$. The production of pro-inflammatory cytokines (IL-1 $\beta$, IL-6) was increased among DCs co-cultured with chemotherapy-treated T.T cells. There was no significant change in the production of IL-10 by DCs stimulated with 5-FU and/or CDDP (Figure 3).
To investigate the role of HMGB1 in mediating DC maturation by supernatants from chemotherapy-treated T.T and KYSE30 cells, we tested the phenotypic changes in DCs stimulated with supernatants from chemically stressed cancer cells. We found that stimulation with supernatants of 5FU/CDDP-treated cancer cell lines induced the up-regulation of HLA-DR, CD80, CD86, and the expression of LAMP-3 on monocyte-derived DCs in comparison to stimulation with untreated supernatants (Figure 4A). In addition, DCs cocultured with supernatants of 5-FU/CDDP-treated T.T cells and KYSE30 cells showed a decreased uptake of FITC-Dextran in comparison to the untreated control group $(p<0.05)$ (Figure 4B). Next, we investigated the impact of chemotherapeutic treatment on the T cell proliferation capacity of DCs. As shown in Figure 5 , monocyte-derived DCs co-cultured with supernatants of 5FU and/or CDDP-treated tumor cells showed a significant increase in T cell proliferation in comparison to untreated cells. The results were similar in both T.T and KYSE 30 cell lines.

The phenotype of tumor infiltrating DCs of surgical specimens and the relationship with the chemotherapeutic 

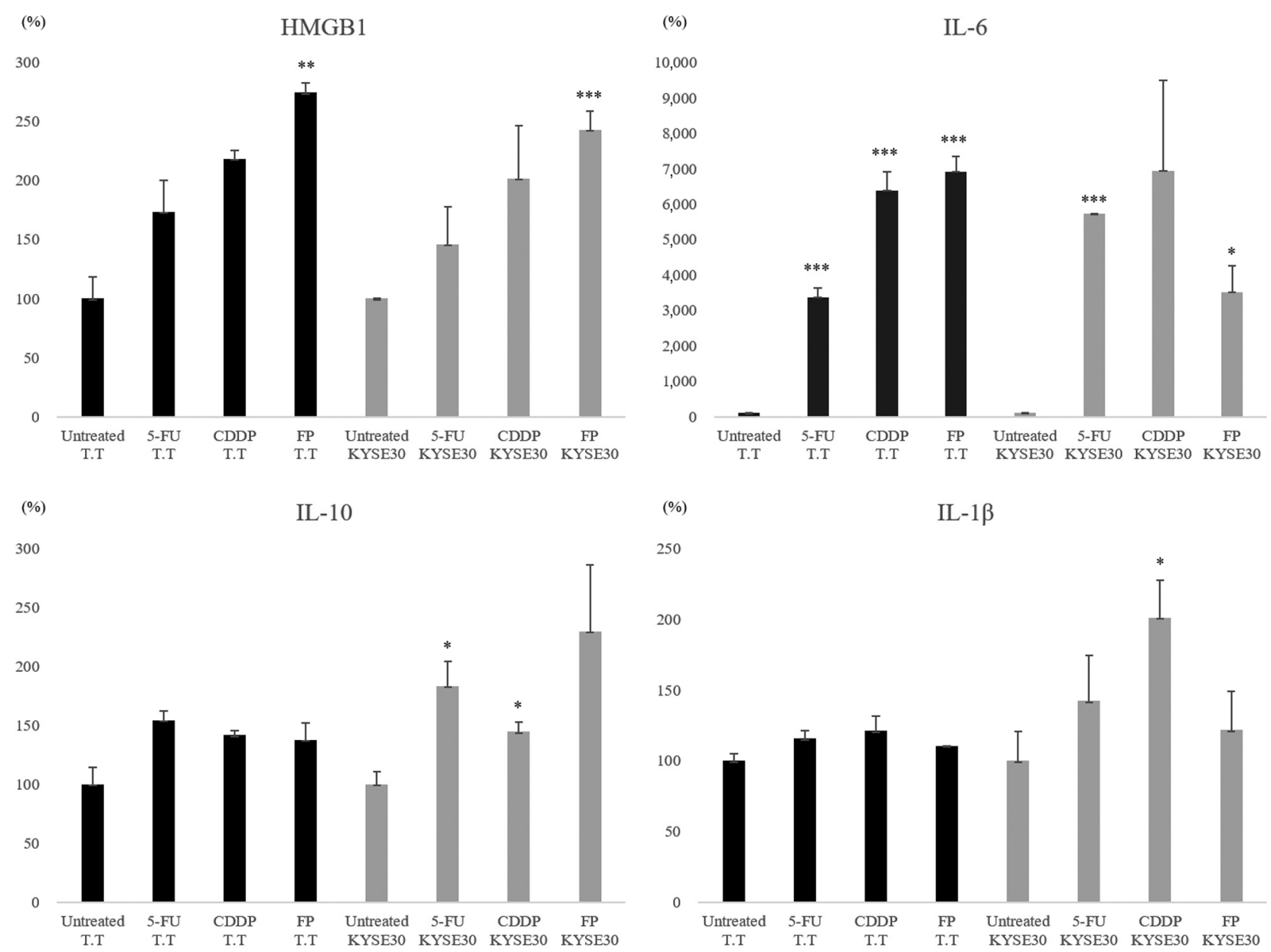

Figure 3. The extracellular release of HMGB1 induced by chemical drugs and cytokine production by dendritic cells (DCs) stimulated with supernatants of chemically stressed T.T cells. The release of HMGB1 into the cell supernatants at 48 h after treatment with 5-FU and/or CDDP was significantly increased in comparison to the release in the untreated control group $(p<0.05)$. The production of pro-inflammatory cytokines $(I L-1 \beta$, IL-6) was increased among DCs co-cultured with chemical drug-treated tumor cells. $* * p<0.01$, ***p<0.001, in comparison to control (untreated) cells.

effect. Next, we isolated DCs from tissues and investigated the relationship between the phenotype, including LAMP-3 expression, and the histological changes after chemotherapy. CD11c+ DCs isolated from surgical specimens showed a more activated phenotype, reflecting the increased expression of CD80 ( $p=0.001)$, and LAMP-3 $(p<0.001)$ and PD-L1 expression in comparison to peripheral monocytederived immature DCs (Figure 6). Focusing on the effect of NAC, the expression of LAMP-3 was significantly elevated in cases in which the effect of NAC was Grade $\geq 1 \mathrm{~b}$ in comparison to Grade $\leq 1$ a cases (Figure 7).

\section{Discussion}

In this study, we investigated the induction of ICD by 5-FU or CDDP, which are key drugs used as neoadjuvant chemotherapy for ESCC. We found the release of HMGB1 into cancer cell supernatants and DC maturation in vitro. Our study suggested that chemotherapy could alter the local immune environment.

Tumor infiltrating mature DCs have been reported to be correlated with a good prognosis in many different types of cancer, including ESCC (10). We previously reported that infiltrating DCs expressing LAMP-3, which is up-regulated on the surface of mature DCs, is an important prognostic factor in ESCC (11). Briefly, we showed that the number of infiltrating LAMP-3 DCs was correlated with the number of intratumoral CD8-T cells. Our report indicated that LAMP$3+$ mature DCs may present tumor-antigens to T cells and activate $\mathrm{T}$ cells in the tumor microenvironment of ESCC.

Regarding the effect of NAC on local immunity, it has been reported that there was no decrease in TILs (tumor infiltrating 
A

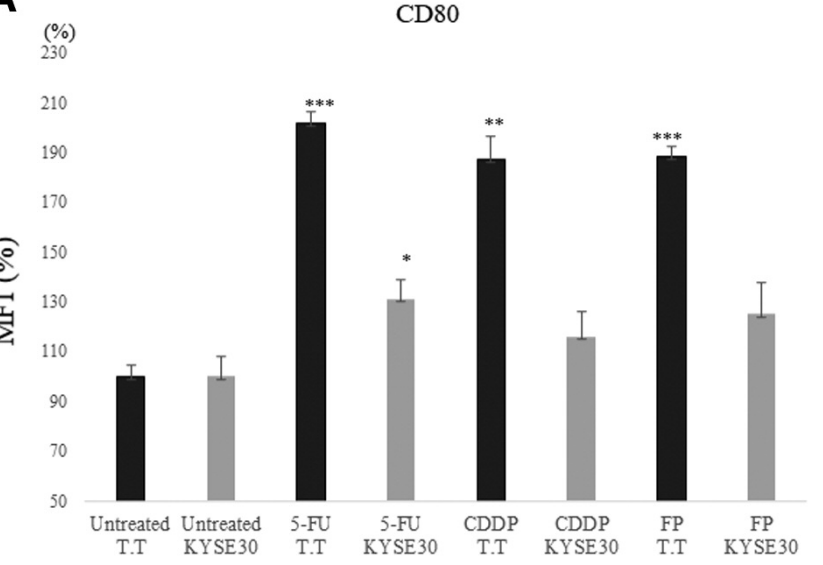

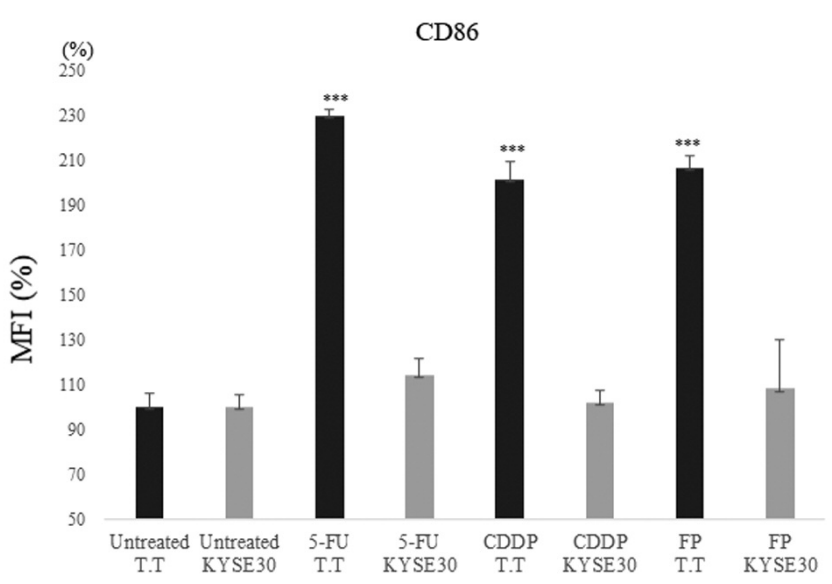

HLA-DR

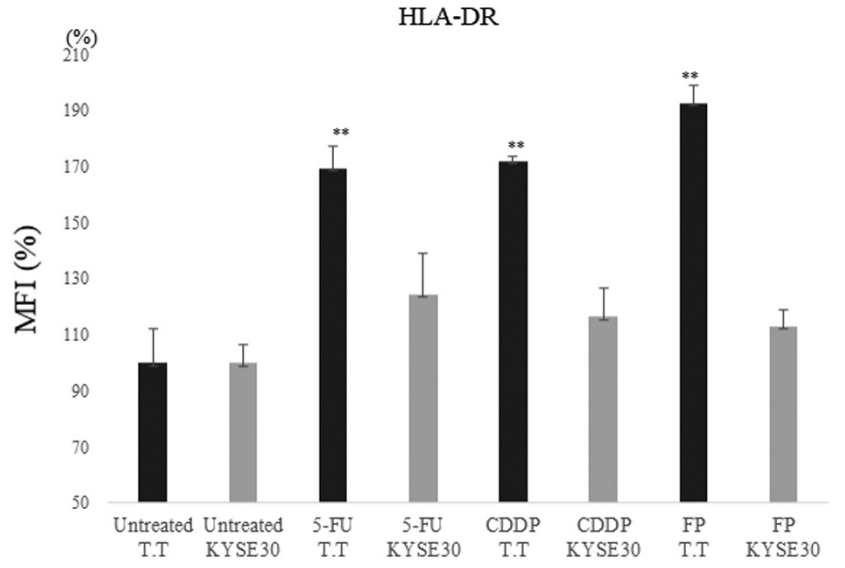

(\%)

LAMP-3

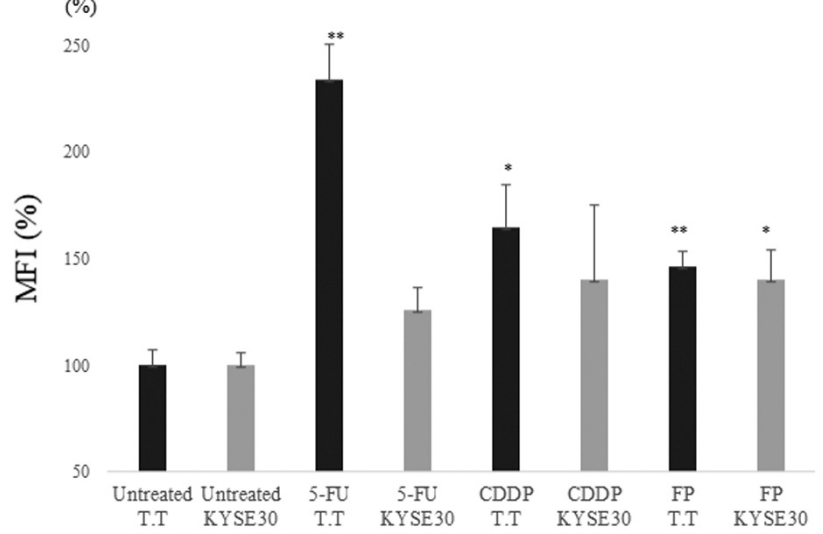

B

$(\%)$

FITC-Dextran

140

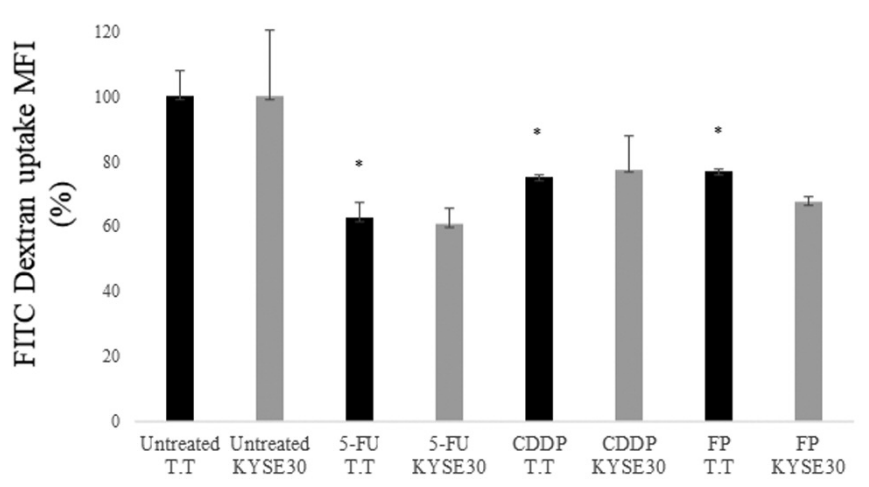

Figure 4. The phenotype of DCs after interaction with cytostatic-killed T.T cells. A. Stimulation with supernatants of 5-FU and/or CDDP-treated tumor cells induced the up-regulation of HLA-DR, CD80, CD86, and the expression of LAMP-3 on monocyte-derived DCs in comparison to stimulation with untreated supernatants. $* p<0.05$, **p<0.01, ***p<0.001, in comparison to control (untreated) cells. B. DCs co-cultured with chemical drug-treated tumor cells showed a modest uptake of FITC-Dextran in comparison to the untreated control group ( $p<0.05)$. ${ }^{p}<0.05$, $* * p<0.01, * * * p<0.001$, in comparison to control (untreated) cells. 

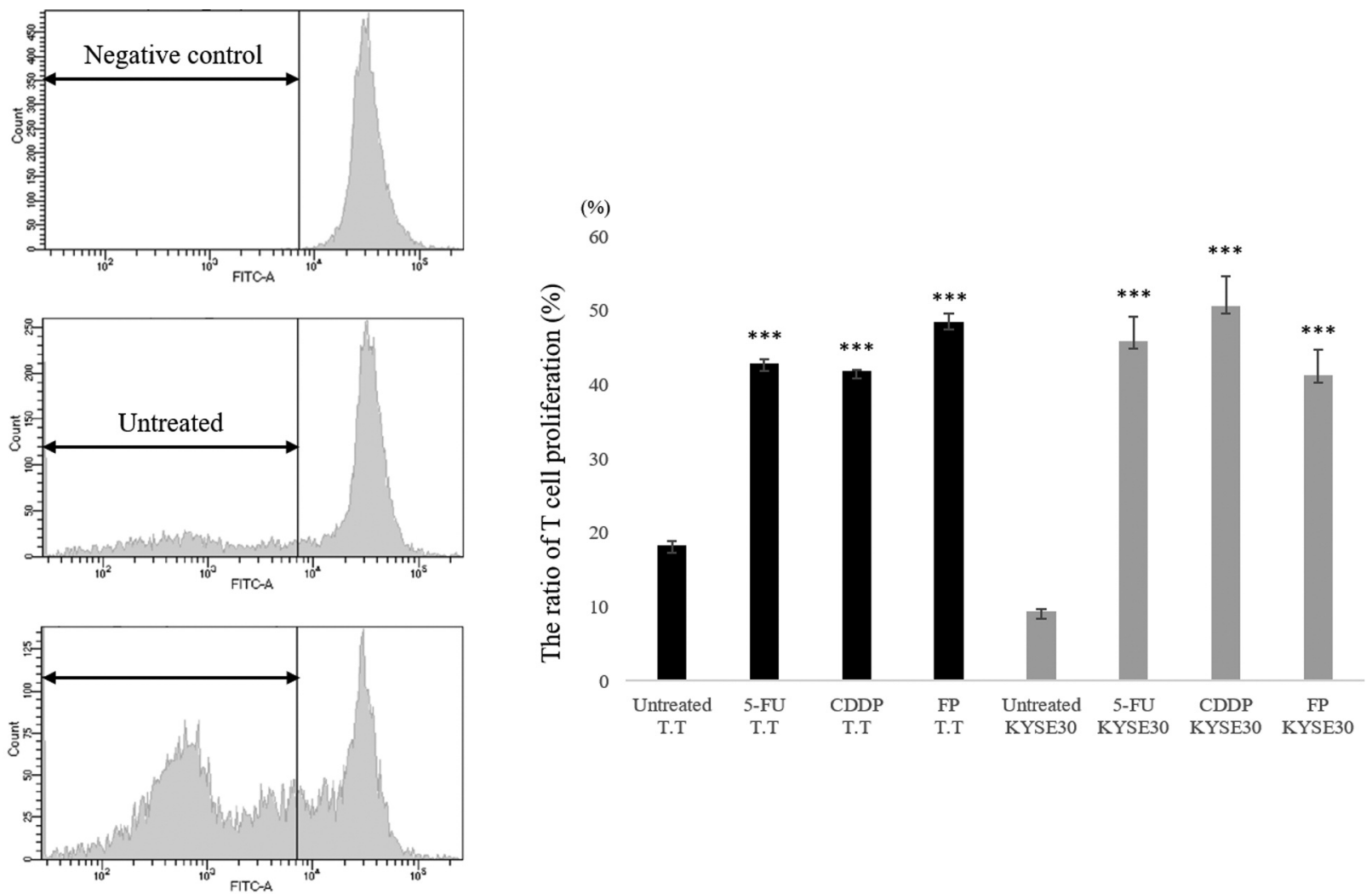

Figure 5. Evaluation of functional up-regulation of DCs by Allo-MLR. Monocyte-derived DCs co-cultured with 5-FU and/or CDDP-treated tumor cells showed a significant increase in $T$ cell proliferation in comparison to untreated cells $(p<0.001) . *^{*}<0.05$, ***p<0.001, in comparison to control (untreated) cells.

lymphocytes) and LAMP-3 DCs after NAC in lung cancer, and that there was an increase in TILs and the tissue expression of PD-L1 after NAC in ovarian cancer $(12,13)$. We showed that the increase in tumor infiltrating mature LAMP-3 DCs was associated with a histological effect by NAC and a favorable prognosis in ESCC. Thus, we found that DCs were both phenotypically and functionally activated by cancer cells treated with 5-FU/CDDP. Some reports have indicated that 5-FU or CDDP induce the release of HMGB1 from dying cells (14-21). It was reported that colorectal cancer cells treated with 5-FU released high levels of HMGB1, and that through these DCs induced the proliferation of IFN- $\gamma$ producing Th1 cells (22). Additionally, platinum drugs, including CDDP, enhanced the phenotypic maturation of blood myeloid DCs upon interaction with platinum-treated tumor cells, and CD $1 \mathrm{c}^{+} \mathrm{DCs}$ treated with these platinum drugs efficiently stimulated the allogeneic production of $\mathrm{T}$ cells in experiments using human melanoma and testicular carcinoma cells (23). Our results imply that NAC using 5-FU/CDDP for ESCC could induce ICD in vitro. However, there is still little information about ICD for ESCC. It has been reported that tumor antigen-specific T-cell responses were induced in patients with ESCC following chemoradiation, along with the elevation of HMGB1 in patients' serum (24). The frequency of FOXP3+ Tregs was negatively correlated with the therapeutic response (meaning that few FOXP3+ T cells were found in patients that responded to chemoradiation) as well as with cancer-specific survival (25). In the present study, we confirmed that LAMP-3 was highly up-regulated in DCs derived from ESCC with a pathological response to NAC using surgical specimens. Our data also showed that DCs from the surgical specimens showed significantly higher expression of PD-L1 compared to monocyte-derived immature DCs. These results suggest increased local production of IFN- $\gamma$ by $\mathrm{T}$ cells, but significant expression of PD-L1 may lead to immunosuppression. We showed, for the first time in a human clinical study, that ICD was induced in ESCC by proving the maturation of DCs. Furthermore, in contrast to the previous reports, our study also suggested that chemotherapy alone could induce ICD in ESCC. Our data suggest that the effect of NAC on the immune microenvironment is not negative and may enhance the local immune response.

The present study is associated with several limitations. Firstly, the doses of the anticancer drugs used in vitro differed from the clinical doses. The exact dose of the anti-cancer drug 


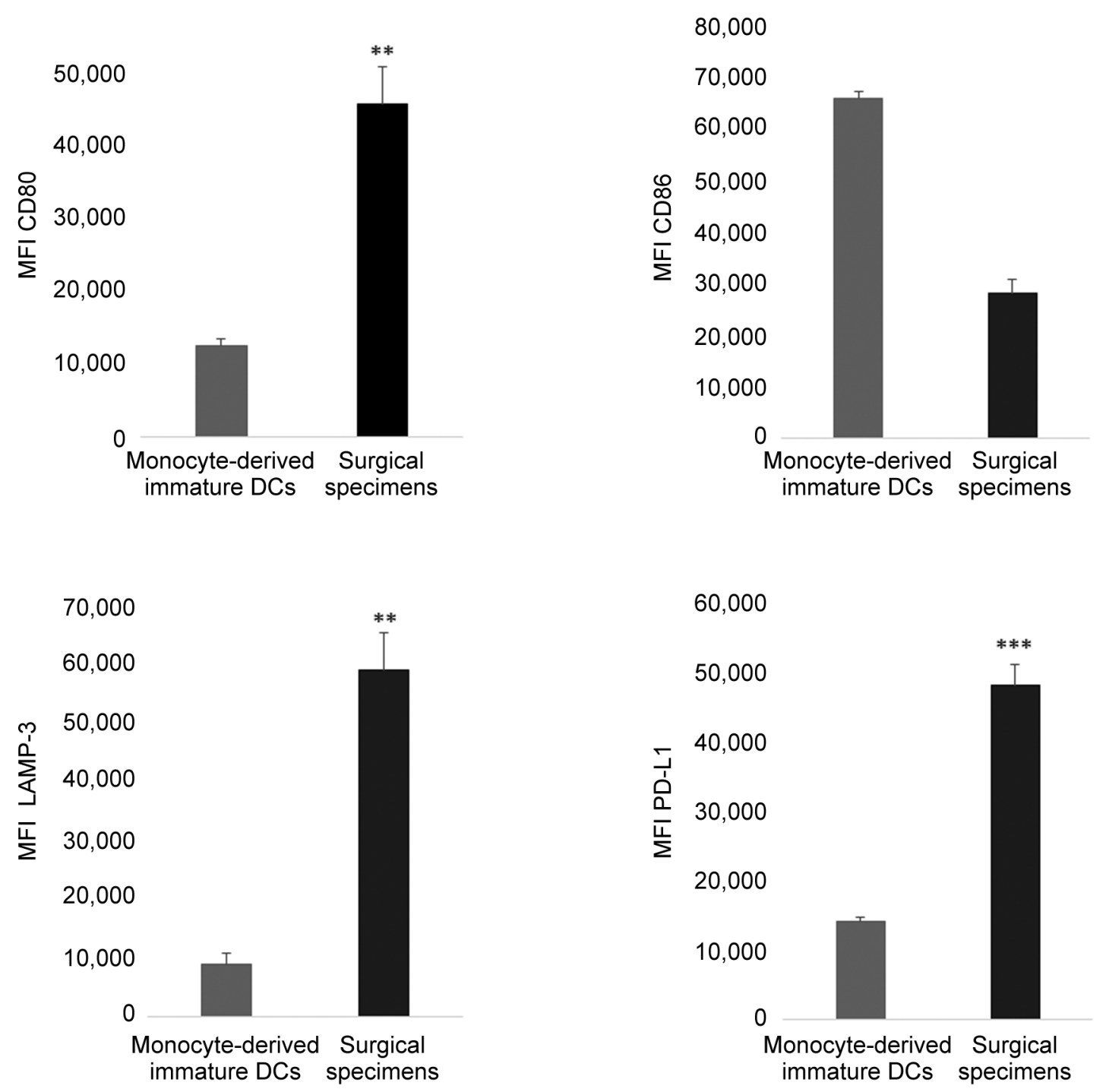

Figure 6. The phenotype and expression of PD-L1 of tumor-infiltrating dendritic cells (DCs) of surgical specimens in comparison to monocytederived immature DCs. DCs isolated from ESCC specimens showed a more activated phenotype in ESCC CD11c+DCs, reflecting the increased expression of CD80 ( $p=0.001)$, and LAMP-3 $(p<0.001)$ in comparison to peripheral monocyte-derived immature DCs. The mean fluorescence intensity (MFI) is shown. *p<0.05, **p<0.01, ***p<0.001, in comparison to control (monocyte-derived immature DCs).

locally at the tumor site is unclear. However, the plasma concentrations of 5-FU when using the standard dose for ESCC was $0.53-1.14 \mu \mathrm{M}(26)$. Furthermore, the Cmax concentrations for CDDP in the plasma of patients are 19-22 $\mu \mathrm{M}(27,28)$. These doses were less than those used in our experiments. Secondly, activation of DCs in the tumor local site was observed, but the detailed mechanism underlying how it promoted invasion of $\mathrm{T}$ cells and induced anti-tumor immunity was not revealed. Further investigations will be required to elucidate the precise mechanism through which NAC affects the maturation of DCs in ESCC.

\section{Conflicts of Interest}

The Authors have no conflicts of interest to declare in relation to this study.

\section{Authors' Contributions}

J.N. and S.D. performed the experiments. M.Y., Y.M., T.T., T.T., L.S. and K.M. contributed to the collection of samples, analysis, and data management. H.T. contributed to the interpretation of data and review of the article. M.O. provided supervision of experiments. All Authors read and approved the manuscript. 

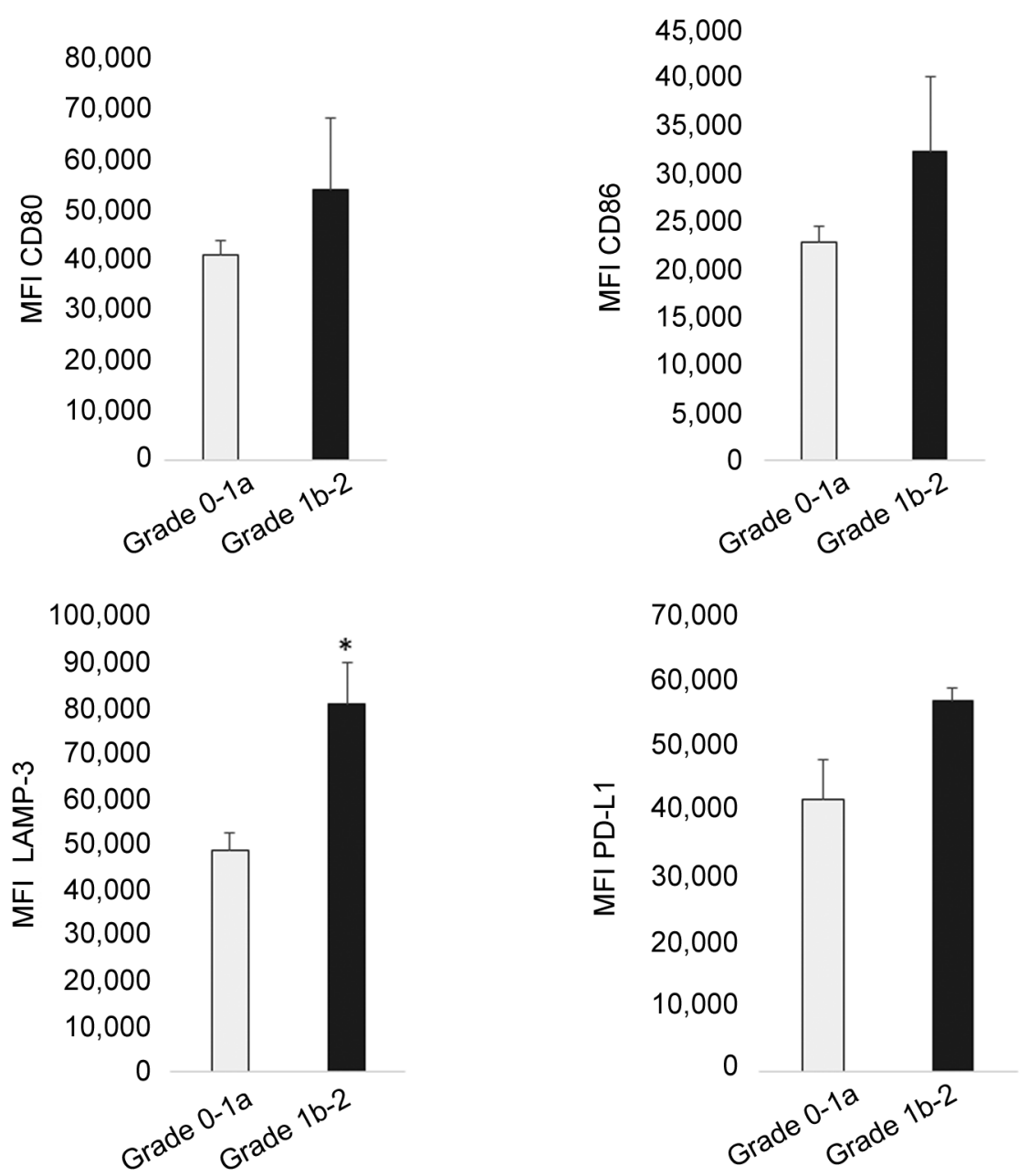

Figure 7. The phenotype and expression of PD-L1 of tumor-infiltrating DCs of surgical specimens based on the pathological effect of NAC. Patients were classified into two groups based on the pathological effect of NAC (Grade0-1a or Grade1b-2). The expression of LAMP-3 was significantly elevated in cases in which the effect of NAC was Grade $\geq 1 b$ in comparison to Grade $\leq 1$ a cases. The mean fluorescence intensity (MFI) is shown. $* p<0.05, * * p<0.01, * * * p<0.001$, in comparison to control (Grade 0-1a).

\section{References}

1 Ando N, Kato H, Igaki H, Shinoda M, Ozawa S, Shimizu H, Nakamura T, Yabusaki H, Aoyama N, Kurita A, Ikeda K, Kanda T, Tsujinaka T, Nakamura $\mathrm{K}$ and Fukuda $\mathrm{H}$ : A randomized trial comparing postoperative adjuvant chemotherapy with cisplatin and 5-fluorouracil versus preoperative chemotherapy for localized advanced squamous cell carcinoma of the thoracic esophagus (jcog9907). Ann Surg Oncol 19(1): 68-74, 2012. PMID: 21879261. DOI: 10.1245/s10434-011-2049-9

2 Kato $\mathrm{H}$ and Nakajima M: Treatments for esophageal cancer: A review. Gen Thorac Cardiovasc Surg 61(6): 330-335, 2013. PMID: 23568356. DOI: 10.1007/s11748-013-0246-0

3 Garg AD, Dudek-Peric AM, Romano E and Agostinis P: Immunogenic cell death. Int J Dev Biol 59(1-3): 131-140, 2015. PMID: 26374534. DOI: $10.1387 / \mathrm{ijdb} .150061 \mathrm{pa}$
4 Kono K, Mimura K and Kiessling R: Immunogenic tumor cell death induced by chemoradiotherapy: Molecular mechanisms and a clinical translation. Cell Death Dis 4: e688, 2013. PMID: 23788045. DOI: $10.1038 /$ cddis.2013.207

5 Gardner A and Ruffell B: Dendritic cells and cancer immunity. Trends Immunol 37(12): 855-865, 2016. PMID: 27793569. DOI: 10.1016/j.it.2016.09.006

6 de Saint-Vis B, Vincent J, Vandenabeele S, Vanbervliet B, Pin JJ, Ait-Yahia S, Patel S, Mattei MG, Banchereau J, Zurawski S, Davoust J, Caux C and Lebecque S: A novel lysosomeassociated membrane glycoprotein, dc-lamp, induced upon dc maturation, is transiently expressed in mhc class ii compartment. Immunity 9(3): 325-336, 1998. PMID: 9768752. DOI: 10.1016/ s1074-7613(00)80615-9

7 Barois N, de Saint-Vis B, Lebecque S, Geuze HJ and Kleijmeer MJ: Mhe class ii compartments in human dendritic cells undergo 
profound structural changes upon activation. Traffic 3(12): 894-905, 2002. PMID: 12453152. DOI: 10.1034/j.1600-0854.2002.31205.x

8 Lin EW, Karakasheva TA, Hicks PD, Bass AJ and Rustgi AK: The tumor microenvironment in esophageal cancer. Oncogene 35(41): 5337-5349, 2016. PMID: 26923327. DOI: 10.1038/ onc.2016.34

9 Shimada $\mathrm{Y}$, Imamura $\mathrm{M}$, Wagata $\mathrm{T}$, Yamaguchi $\mathrm{N}$ and Tobe $\mathrm{T}$ : Characterization of 21 newly established esophageal cancer cell lines. Cancer 69(2): 277-284, 1992. PMID:1728357. DOI: 10.1002/1097-0142(19920115)69:2<277::aid-cncr28206 $90202>3.0 . c 0 ; 2-\mathrm{c}$

10 Karthaus N, Torensma R and Tel J: Deciphering the message broadcast by tumor-infiltrating dendritic cells. Am J Pathol 181(3): 733-742, 2012. PMID: 22796439. DOI: 10.1016/j.ajpath. 2012.05.012

11 Nishimura J, Tanaka H, Yamakoshi Y, Hiramatsu S, Tamura T, Toyokawa T, Muguruma K, Maeda K, Hirakawa K and Ohira M: Impact of tumor-infiltrating lamp-3 dendritic cells on the prognosis of esophageal squamous cell carcinoma. Esophagus 16(4): 333-344, 2019. PMID: 30968254. DOI: 10.1007/s10388019-00669-w

12 Khairallah AS, Genestie C, Auguste A and Leary A: Impact of neoadjuvant chemotherapy on the immune microenvironment in advanced epithelial ovarian cancer: Prognostic and therapeutic implications. Int J Cancer 143(1): 8-15, 2018. PMID: 29218796. DOI: $10.1002 / \mathrm{ijc} .31200$

13 Remark R, Lupo A, Alifano M, Biton J, Ouakrim H, Stefani A, Cremer I, Goc J, Regnard JF, Dieu-Nosjean MC and Damotte D: Immune contexture and histological response after neoadjuvant chemotherapy predict clinical outcome of lung cancer patients. Oncoimmunology 5(12): e1255394, 2016. PMID: 28123901. DOI: 10.1080/2162402X.2016.1255394

14 Mihailidou C, Chatzistamou I, Papavassiliou AG and Kiaris H: Improvement of chemotherapeutic drug efficacy by endoplasmic reticulum stress. Endocr Relat Cancer 22(2): 229-238, 2015. PMID: 25670032. DOI: 10.1530/ERC-15-0019

15 Cirone M, Garufi A, Di Renzo L, Granato M, Faggioni A and D'Orazi G: Zinc supplementation is required for the cytotoxic and immunogenic effects of chemotherapy in chemoresistant p53-functionally deficient cells. Oncoimmunology 2(9): e26198, 2013. PMID: 24228232. DOI: 10.4161/onci.26198

16 Aranda F, Bloy N, Galluzzi L, Kroemer G and Senovilla L: Vitamin b6 improves the immunogenicity of cisplatin-induced cell death. Oncoimmunology 3(9): e955685, 2014. PMID: 25941619. DOI: $10.4161 / 21624011.2014 .955685$

17 Martins I, Kepp O, Schlemmer F, Adjemian S, Tailler M, Shen S, Michaud M, Menger L, Gdoura A, Tajeddine N, Tesniere A, Zitvogel L and Kroemer G: Restoration of the immunogenicity of cisplatin-induced cancer cell death by endoplasmic reticulum stress. Oncogene 30(10): 1147-1158, 2011. PMID: 21151176. DOI: 10.1038 /onc. 2010.500

18 Golden EB, Frances D, Pellicciotta I, Demaria S, Helen Barcellos-Hoff $\mathrm{M}$ and Formenti SC: Radiation fosters dosedependent and chemotherapy-induced immunogenic cell death. Oncoimmunology 3: e28518, 2014. PMID: 25071979. DOI: 10.4161/onci.28518

19 Obeid M, Tesniere A, Ghiringhelli F, Fimia GM, Apetoh L, Perfettini JL, Castedo M, Mignot G, Panaretakis T, Casares N, Metivier D, Larochette N, van Endert P, Ciccosanti F, Piacentini M, Zitvogel L and Kroemer G: Calreticulin exposure dictates the immunogenicity of cancer cell death. Nat Med 13(1): 54-61, 2007. PMID: 17187072. DOI: 10.1038/nm1523

20 Aranda F, Bloy N, Pesquet J, Petit B, Chaba K, Sauvat A, Kepp O, Khadra N, Enot D, Pfirschke C, Pittet M, Zitvogel L, Kroemer G and Senovilla L: Immune-dependent antineoplastic effects of cisplatin plus pyridoxine in non-small-cell lung cancer. Oncogene 34(23): 3053-3062, 2015. PMID: 25065595. DOI: 10.1038/onc.2014.234

21 Yamamura Y, Tsuchikawa T, Miyauchi K, Takeuchi S, Wada M, Kuwatani T, Kyogoku N, Kuroda A, Maki T, Shichinohe T and Hirano S: The key role of calreticulin in immunomodulation induced by chemotherapeutic agents. Int J Clin Oncol 20(2): 386394, 2015. PMID: 24972573. DOI: 10.1007/s10147-014-0719-x

22 Fang H, Ang B, Xu X, Huang X, Wu Y, Sun Y, Wang W, Li N, Cao $\mathrm{X}$ and Wan T: Tlr4 is essential for dendritic cell activation and anti-tumor $\mathrm{t}$-cell response enhancement by damps released from chemically stressed cancer cells. Cell Mol Immunol 11(2): 150-159, 2014. PMID: 24362470. DOI: 10.1038/cmi.2013.59

23 Di Blasio S, Wortel IM, van Bladel DA, de Vries LE, Duivemande Boer T, Worah K, de Haas N, Buschow SI, de Vries IJ, Figdor CG and Hato SV: Human cd1c(+) dcs are critical cellular mediators of immune responses induced by immunogenic cell death. Oncoimmunology 5(8): e1192739, 2016. PMID: 27622063. DOI: $10.1080 / 2162402 X .2016 .1192739$

24 Suzuki Y, Mimura K, Yoshimoto Y, Watanabe M, Ohkubo Y, Izawa $\mathrm{S}$, Murata $\mathrm{K}$, Fujii $\mathrm{H}$, Nakano $\mathrm{T}$ and Kono $\mathrm{K}$ : Immunogenic tumor cell death induced by chemoradiotherapy in patients with esophageal squamous cell carcinoma. Cancer Res 72(16): 3967-3976, 2012. PMID: 22700877. DOI: 10.1158/ 0008-5472.CAN-12-0851

25 Vacchelli E, Semeraro M, Enot DP, Chaba K, Poirier Colame V, Dartigues P, Perier A, Villa I, Rusakiewicz S, Gronnier C, Goere D, Mariette C, Zitvogel L and Kroemer G: Negative prognostic impact of regulatory t cell infiltration in surgically resected esophageal cancer post-radiochemotherapy. Oncotarget 6(25): 20840-20850, 2015. PMID: 26369701. DOI: 10.18632/oncotarget.4428

26 Kuwahara A, Yamamori M, Nishiguchi K, Okuno T, Chayahara N, Miki I, Tamura T, Kadoyama K, Inokuma T, Takemoto Y, Nakamura T, Kataoka $\mathrm{K}$ and Sakaeda T: Effect of doseescalation of 5-fluorouracil on circadian variability of its pharmacokinetics in japanese patients with stage iii/iva esophageal squamous cell carcinoma. Int J Med Sci 7(1): 48-54, 2010. PMID: 20151048. DOI: 10.7150/ijms.7.48

27 Dijkgraaf EM, Heusinkveld M, Tummers B, Vogelpoel LT, Goedemans R, Jha V, Nortier JW, Welters MJ, Kroep JR and van der Burg SH: Chemotherapy alters monocyte differentiation to favor generation of cancer-supporting $\mathrm{m}^{2}$ macrophages in the tumor microenvironment. Cancer Res 73(8): 2480-2492, 2013. PMID: 23436796. DOI: 10.1158/0008-5472.CAN-12-3542

28 Kroep JR, Smit EF, Giaccone G, Van der Born K, Beijnen JH, Van Groeningen CJ, Van der Vijgh WJ, Postmus PE, Pinedo HM and Peters GJ: Pharmacology of the paclitaxel-cisplatin, gemcitabine-cisplatin, and paclitaxel-gemcitabine combinations in patients with advanced non-small cell lung cancer. Cancer Chemother Pharmacol 58(4): 509-516, 2006. PMID: 16523337. DOI: $10.1007 / \mathrm{s} 00280-006-0191-\mathrm{z}$

Received December 5, 2020

Revised January 3, 2021

Accepted January 4, 2021 